\title{
Política de saúde e de cuidados continuados integrados em Portugal. O planeamento da alta em Serviço Social
}

\author{
Maria Irene Lopes B. de Carvalho \\ Universidade Lusófona, Lisboa \\ Este artigo mantém a ortografia vigente em Portugal
}

Política de saúde e de cuidados continuados integrados em Portugal. O planeamento da alta em Serviço Social

Resumo: Este texto pretende evidenciar a construção da política de cuidados continuados integrados, social e de saúde, no âmbito da política de saúde em Portugal, destacando o planeamento da alta em Serviço Social. Desde 2006 que os cuidados continuados são assumidos como direitos e integrados na política e no sistema de saúde. A profissão do Serviço Social tem recebido destaque no processo de planeamento das altas e no desenvolvimento de procedimentos implícitos na relação de ajuda, nomeadamente no acolhimento e diagnóstico, reuniões e pareceres, planos de ação, acompanhamento e avaliação do processo e integração na comunidade. A dimensão técnico-operativa do Serviço Social no planeamento da alta contribui para destacar a profissão no sistema de saúde, potenciar o usufruto de cuidados, melhorar o bem-estar dos doentes e das famílias, assim como consolidar a profissão de Serviço Social na sociedade.

Palavras-chave: Política de saúde. Cuidados continuados. Planeamento da alta. Serviço Social.

\section{Healthcare Policy and Continued Integrated Care in Portugal. The Planning of Release in Social} Work

Abstract: This paper presents the construction of the policy for integrated and continued, social assistance and healthcare in the realm of healthcare policy in Portugal, highlighting the planning for release in Social Work. Since 2006, when continued care was recognized as a right and integrated into policy and the healthcare system, the Social Work profession has been highlighted in this process of planning for release and in the development of procedures that are implicit in the relation of assistance, particularly in the reception and diagnosis, meetings and reports, action plans, accompaniment and evaluation of the process and integration in the community. The technical-operative dimension of Social Work in planning for release highlights the role of the profession within the healthcare system, improving access to the benefits of care, the well-being of the ill and of families, and consolidates the Social Work profession in society. Keywords: Healthcare policy. Continuing care. Planning for release. Social Work. 


\section{Introdução}

Este artigo destaca a construção da política de cuidados continuados integrados - saúde e social - no âmbito do sistema de saúde em Portugal e evidencia a intervenção do Serviço Social nesse domínio nomeadamente no planeamento da alta. Este procedimento tem permitido ao Serviço Social destacar-se na intervenção em saúde e na rede de cuidados continuados integrados em particular.

Esta análise da política, de cuidados continuados integrados que agora se apresenta, resulta da experiência da autora como interventora na construção dessa rede e de processos formativos pós-graduados a profissionais que desenvolvem atividade neste domínio, assim como da pesquisa efetuada no âmbito do doutoramento em Serviço Social, sobre a construção da política de cuidados em Portugal.

Num primeiro momento situamos a construção do serviço nacional de saúde em Portugal e a necessidade de cuidados continuados integrados, reportando-nos ao processo de construção desta rede no âmbito da política de saúde. No segundo momento analisamos a relação do Serviço Social no planeamento da alta e destacamos a especificidade técnico-operativa da profissão do Serviço Social neste domínio.

\section{Da política de saúde à política de cuidados continuados integrados}

De uma conceção de saúde como ausência de doença, a saúde foi definida em 1947 pela Organização Mundial da Saúde (OMS) como um Estado completo de bem-estar orientado por determinantes biopsicossociais (REIS, 2005). A complexidade das situações e a evolução tecnológica e científica reconfiguraram a noção de saúde entendida como o conjunto de esforços realizados coletivamente e individualmente para que se concretize o potencial máximo de saúde a que podemos aspirar (LOUREIRO; MIRANDA, 2010). Remete para o conceito de promoção da saúde e para um conjunto de determinantes alargados tais como: os comportamentais, sociais económicos, políticos e ambientais, onde as significações e as experiências dos sujeitos ganham relevo no modelo de saúde que se quer holístico (REIS, 2005, p. 26).

Esta ideia de saúde alia-se àquela defendida na Carta de Otawa em 1986, que considera que promover a saúde é "um processo que visa criar as condições que permitem aos indivíduos e aos grupos controlar a sua saúde, a dos grupos em que se integram e agir sobre os fatores que a influenciam" (LOUREIRO; MIRANDA, 2010, p. 31). A saúde assume-se como um direito fundamental a todo o ser humano, sem distinção de raça, religião, credo político e condição económica e social (OMS, 2011, p. 1).

Em Portugal, este direito foi consubstanciado na constituição da república de 1976, logo após o derrube da ditadura. O Serviço Nacional de Saúde, da responsabilidade do Estado e de acesso universal, foi instituído em 1979, com a Lei n. 56/1979, a qual definia o Serviço Nacional de Saúde como "uma rede de órgãos e serviços, dependentes do Estado, com gestão descentralizada e democrática que visava a prestação de saúde a toda a população", sendo o seu acesso "universal, mas sem prejuízo da introdução de taxas moderadoras". Integrava todos os cuidados de saúde, nomeadamente a promoção e vigilância, a prevenção, o diagnóstico, o tratamento e a reabilitação médico-social. Nesta linha de atuação foram criados serviços hospitalares, centros de saúde na comunidade e outras unidades de prestação de cuidados de saúde especializadas ${ }^{1}$.

O Serviço Nacional de Saúde representa um dos pilares fundamentais do Estado de bem-estar social em Portugal, contribuiu grandemente para o desenvolvimento social e para a mudança de indicadores como o da mortalidade infantil, o aumento de anos de sobrevida de doentes crónicos e de pessoas com 65 anos ou mais, produzindo, assim, padrões de bem-estar idênticos a países tidos como os mais desenvolvidos.

Num contexto de globalização e de crise económica e financeira do Estado, este sistema de proteção está a ser posto em causa e o governo atual tem implementado mudanças cuja tendência é a sua privatização². Esta privatização passa por contratos que atribuem aos privados a gestão, por exemplo, de unidades hospitalares. Esta questão, segundo Dominelli (2013), é recorrente também em países europeus. Consequentemente, tem surgido uma série de organizações de saúde privadas que competem com o setor público em determinadas áreas, nomeadamente hospitais com internamentos, consultas e exames, especialmente em áreas da saúde mais lucrativas. O resultado desta política neoliberal tem como consequência o aumento do custo da saúde para as famílias ${ }^{3}$.

A mudança de paradigma da saúde, de uma visão patogénica para uma salutogénica, permitiu que as pessoas vivessem mais anos com doenças crónicas (LOUREIRO; MIRANDA, 2010), e são estas pessoas que mais utilizam os serviços de saúde, seja em cuidados primários - as unidades de saúde familiar - seja em cuidados hospitalares e diferenciados (CAMPOS, 2008). São os doentes crónicos e os doentes mais velhos que necessitam de cuidados continuados, de saúde e social, logo após a alta hospitalar.

Em Portugal, até final dos anos noventa, as pessoas que necessitassem de cuidados continuados eram encaminhadas para o domicílio, lares de doentes ou clínicas de retaguarda protocoladas com alguns hospitais 
para dar respostas à alta clínica deste tipo de doentes. Segundo Campos (2008), as respostas eram pontuais, não eram integradas e coordenadas a nível nacional. Este fato penalizava grandemente os doentes e as organizações de saúde, os hospitais, que se viam com um custo acrescido porque os doentes tinham de permanecer mais tempo nos serviços após a alta clínica. Além disso, os sucessivos reinternamentos decorrentes de altas não planeadas e não integradas numa rede de cuidados suficientemente forte, constituíam um problema.

Neste contexto algumas questões emergiram: como responder às necessidades dos doentes, com qualidade e menores custos para o setor da saúde? A resposta era clara: seria necessário desenvolver uma rede de cuidados continuados, que integrasse os cuidados em saúde e os sociais. Significaria assumi-los como direito, não dependentes do poder aquisitivo das famílias (CARVALHO, 2012b).

A rede assumia-se como uma interface entre cuidados primários - comunitários - e cuidados secundários - hospitalares ${ }^{4}-($ BOQUINHAS, 2012, p. 87). Assim, esta rede teria de ser contratualizada entre o Estado e os restantes agentes económicos, as instituições de solidariedade social e as autarquias, pois são estas que têm um conhecimento sobre a realidade social onde os problemas ocorrem. Foi a partir desta ideia que foi construída a rede de cuidados continuados integrados, existentes em Portugal.

\subsection{A construção da política de cuidados continuados integrados}

Os cuidados continuados são aqueles organizados e prestados formalmente por instituições, na comunidade, e por profissionais pagos. Em Portugal, emergiram com a criação do programa de apoio integrado a idosos, o Paii ${ }^{5}$ (Despacho Conjunto n. 166, 1994, 20 julho). Este programa, pioneiro na prestação de cuidados a doentes, era financiado pelo jogo social nacional denominado de JOKER, e tinha como objetivo: melhorar os cuidados já existentes e desenvolver respostas denominadas inovadoras porque integradas ${ }^{6}$. Aliada a este programa, foi assumida em 1996, pelo ministério da saúde e o da segurança social, a necessidade de criar uma rede de cuidados continuados (Despacho n. 204, de 3 de setembro de 1996) ${ }^{7}$.

As medidas legislativas são consideradas a base da construção da rede de cuidados continuados nos anos seguintes. Desse modo, em 2003 surgiu a primeira lei que instituía a implementação da primeira rede de cuidados continuados integrados (Decreto-lei n. 281, de 2003), que integrava a área social e a saúde, todas as organizações de solidariedade social e as autarquias na organização e prestação de respostas continuadas e integradas. Criava unidades de internamento, unidades de recuperação global e unidades móveis domiciliárias.

Porém, as crescentes necessidades, aliadas à vontade política, quer das orientações da união europeia, quer do governo socialista de então, fizeram com que esta lei fosse substituída pela atual Lei n. 101 de 2006 , dos cuidados continuados, que preconizava um programa alargado a nível nacional, com uma coordenação central e regional, e com respostas na comunidade adequadas a cuidados de reabilitação, de média e de longa duração ${ }^{8}$. Foram criadas: i) unidades de cuidados de internamento com de convalescença, de longa duração, de média duração e de cuidados paliativos; ii) unidades em ambulatório com unidades de dia; iii) equipas de gestão das altas; intra-hospitalares e de cuidados paliativos; e iv) equipas domiciliárias, com cuidados continuados integrados.

A rede define-se como um modelo de respostas diversificadas, com a participação de diferentes tipos de prestadores e articulada através do desenvolvimento de um processo de contratação da prestação de cuidados (CCI, 2013, p. 6). Esta lei possibilitou a criação de respostas com equipas de trabalho multidisciplinar, que alteraram por completo o espetro da intervenção na área da saúde e na área dos cuidados continuados em Portugal (CARVALHO, 2012a; 2012c).

A rede de cuidados continuados, implementada em 2006, está presente em todo o território nacional com todas as tipologias de cuidados previstas. Desde outubro de 2006 até dezembro de 2012 foram implementados um total de 5911 lugares de internamento/camas (CCI, 2013, p. 20) ${ }^{9}$. O número de equipas referenciadoras nos grupamentos de centro de saúde, também aumentou. Fazem parte do circuito de referenciação de base comunitária, existindo 405 equipas referenciadoras nos agrupamentos de centros de saúde em Portugal ${ }^{10}$.

Situada a amplitude da rede quanto ao número de lugares e equipas, é importante aferir o número de pessoas apoiadas. Segundo o relatório da CCI de 2013, desde 2006 a 2012 a rede apoiou 39.663 pessoas, distribuídas da seguinte forma: 15,379 na região Norte; 7,885 na região centro; 7633 na região de Lisboa e vale do tejo; 4286 na região do Alentejo e 4480 no Algarve. Comparando com o número de pessoas dependentes em cada região verifica-se que Algarve e Alentejo são as que apresentam uma taxa mais favorável relativamente à extensão do apoio, enquanto Lisboa e vale do tejo apresenta-se como a região com menos apoio efetivo às pessoas dependentes. A maioria dos doentes internados em 2012 insere-se no grupo etário com idade de 65 e mais anos. Estes representam 81,3\% dos utentes referenciados (CCI, 2013, p. 48). Este fato está de acordo com o envelhecimento da população e com o aumento do número das pessoas com 65 e mais anos na estrutura da população em Portugal, que é de 19,1\% (INE, 2011). 
Contudo, apesar das virtudes desta rede há também alguns aspetos ainda não conquistados, nomeadamente, a cobertura de cuidados ainda não é suficiente, o que faz aumentar a lista de espera. No contexto de crise económica e financeira, esta rede está atualmente bloqueada pela falta de financiamento para o desenvolvimento de novas respostas e para a contratação de profissionais. Este fato é preocupante, pois é nas alturas de crise que os problemas aumentam e, no caso das pessoas idosas, a situação é ainda mais problemática, sobretudo pelo agravamento das condições de bem-estar e de saúde ${ }^{11}$.

\subsection{A participação dos cidadãos no sistema de saúde}

A revolução de abril de 1974 permitiu construir o Serviço Nacional de Saúde. Defendia-se o direito à saúde, incondicional e gratuito. Resultante de uma reinvidiação dos cidadãos foi criada uma das políticas mais emblemáticas deste período, o serviço médico à periferia, que obrigava os médicos a atenderem as zonas do interior e do litorial do país que não tinham serviços de saúde, nem médicos. Mas com o desenvolvimento da rede de cuidados de saúde este serviço foi extinto.

A participação dos cidadãos no sistema de saúde português foi promovida desde a sua construção. Depois do período revolucionário, em 1986, a participação foi formalizada nos denominados gabinetes do utente com o Despacho n. 26 de 1986, que desenvolveu estruturas e gabinetes junto dos hospitais do Serviço Nacional de Saúde e das administrações regionais de saúde. Estes espaços promovem a participação dos cidadãos no que diz respeito à informação, sistematização de reclamações, sugestões e louvores. A partir de 2005 passaram a demoninar-se de gabinete do cidadão ${ }^{12}$.

Para uniformizar estes processos particiativos, o Despacho n. 5081 de 2005 criou o sistema SIM-Cidadão vocacionado para analisar e tratar as exposições dos utentes do Serviço Nacional de Saúde de uma forma atempada e celere, isto é, para responder às expetativas dos cidadãos em tempo útil no que diz respeito à saúde ${ }^{13}$. Os profissionais de Serviço Social são os responsáveis pela gestão destes gabinetes, na maioria dos serviços de saúde.

A participação dos cidadãos nos serviços de saude é efetuada também através de associações de doentes e de defesa do Serviço Nacional de Saúde, como, por exemplo, a associação de defesa dos utentes da saúde, associação em defesa da saúde mental, associação das vítimas dos hospitais, entre outras. Para promover os direitos dos cidadãos na saúde, o sistema inclui ainda um provedor do utente, que funciona como mediador entre os cidadãos e o serviço regional de saúde.

\section{Serviço Social, política de saúde e de cuidados continuados integrados}

Nesse texto assumimos que o Serviço Social pode ser definido como um saber no âmbito das ciências sociais e humanas, e uma prática social que se desenvolve na sociedade, com uma competência científica e técnica, uma relativa autonomia de critérios e, consequentemente, com uma responsabilidade social (CARVALHO et al., 1998). Esta profissão, associada aos direitos humanos, justiça social e dignidade, assume-se como um processo de intervenção profissional que implica os pressupostos de "deciframento analítico da estrutura, da conjuntura e da situação, numa perspetiva relacional e de articulação da participação do sujeito e atuação em redes e vínculos que permitam mediações gerais e particulares de assegurar direitos consubstanciados em estratégias de ação" (FALEIROS, 2011, p. 756).

Nesta definição de Serviço Social estão incluídas as suas principais dimensões: teórico/metodológica; técnico/operativa e ético/política. Em termos teóricos o conhecimento do Serviço Social associa-se às ciências sociais, sobretudo às correntes humanistas, emancipatórias e críticas (PAYNE, 2011). O Serviço Social articula-se com o mundo da vida e dos sistemas, com os problemas sociais, políticas públicas e sociais, com os instrumentos e técnicas de intervenção nestes domínios.

A intervenção do Serviço Social é influenciada pelo modo como a sociedade está organizada, pelos seus princípios, valores e cultura. Os direitos humanos são fundamentais no Serviço Social destacando-se os princípios da autodeterminação, liberdade e participação, assim como a justiça social e a equidade.

A inclusão do Serviço Social no contexto dos cuidados de saúde e continuados integrados é um imperativo de direitos humanos e de dignidade humana. O Serviço Social integrou-se na área da saúde ${ }^{14}$, ainda antes da construção do serviço nacional de saúde. Contudo, foi a partir da construção deste sistema que os assistentes sociais se destacaram na defesa dos direitos dos doentes e em funções técnicas operativas que lhe são atribuídas, tais como conceção, planeamento e intervenção direta junto dos doentes, famílias e comunidades ${ }^{15}$.

Os assistentes sociais evidenciam-se na rede de cuidados continuados por estarem integrados nas unidades de internamento na comunidade em equipas de planeamento das altas de uma forma sistemática e obrigatória 
e em unidades de ambulatório, cuidados paliativos e equipas domiciliárias de uma forma menos sistemática e pontual, pois a sua integração e intervenção decorre do modo como as instituições estão organizadas.

Em termos teórico-metodológicos, um dos modelos de intervenção do Serviço Social que se tem destacado no sistema de saúde e em cuidados continuados, pela sua capacidade de responder aos problemas e de emancipar os indivíduos, é a intervenção psicossocial, individualizada, que integra o modelo de socialização, clínico, conducionista, de crise, transacional, de resolução de problemas entre outros (GARCIA; ROMERO, 2012, p. 43). Este modelo foi adotado pela DGS (2006) para ser desenvolvido na rede de cuidados continuados pelos profissionais de Serviço Social. O modelo de intervenção psicossocial individualizado tem a virtude de ser centrado na pessoa e no seu ambiente, no contexto, e de ser adequado à intervenção em cuidados continuados.

A intervenção individualizada é centrada na pessoa ${ }^{16}$.

\section{A inclusão do Serviço Social no} contexto dos cuidados de saúde e continuados integrados é um imperativo de direitos humanos e de dignidade humana. O relacionamento interpessoal é a base deste modelo, onde a relação de ajuda ganha destaque. Para que esta se efetive é necessário o desenvolvimento de uma relação positiva, onde a empatia, a aceitação, a autenticidade, o respeito e a confidencialidade, constituem-se como pilares da intervenção (GARCIA; ROMERO, 2012). Neste enquadramento, a pessoa é entendida não como um corpo físico e uma mente, mas uma pessoa, como um ser social, com uma dimensão holística.

O modelo psicossocial, individualizado, assume que o comportamento é o resultado de uma série de interações que se produzem entre o pensamento e o meio ambiente social e físico ${ }^{17}$. A intervenção psicossocial remete não só para a compreensão das necessidades e os recursos sociais das pessoas, mas também para o desenvolvimento e mobilização de capacidades no âmbito das relações sociais ${ }^{18}$. Este tipo de intervenção requer um pensamento humanista (PAYNE, 2011; 2012), desafiando o Serviço Social para o comprometimento com as motivações e capacidades humanas e com a responsabilidade social coletiva - direitos humanos, justiça social, bem-estar ${ }^{19}$.

No âmbito da política de saúde e em cuidados continuados, a profissão é conhecida pelo seu papel no planeamento da alta. Como defende Santos et al. (2008, p. 20) a dimensão técnico-operativa representa o conjunto de ações e procedimentos adotados pelo profissional visando à concessão de uma determinada finalidade e dos objetivos de ação. Aí se encontram estratégias táticas, instrumentos e técnicas, conhecimentos específicos, procedimentos, ética, cultura profissional e institucional e realidades particulares. Este manancial técnico operativo requer mediação entre os vários intervenientes e processos ${ }^{20}$.

O processo de planeamento da alta implica um processo de: acolhimento; aprofundamento do diagnóstico; planeamento da intervenção; acompanhamento e avaliação integração no domicílio - meio de origem. Este processo requer instrumentos e técnicas para a elaboração de um plano individual de intervenção ${ }^{21}$ e de um plano individual de cuidados ${ }^{22}$ (DGS, 2006; CARVALHO, 2012a; 2012b; 2012c). São alguns destes procedimentos que iremos explorar de seguida.

\subsection{Intervenção do Serviço Social em cuidados continuados integrados}

Como sabemos, as estadias nos hospitais são temporárias sendo necessário investir no planeamento da alta do doente para o domicílio. O roteiro dos doentes no sistema de saúde inicia-se quando os mesmos entram em contato ou com as unidades de internamento em hospitais, ou em ambulatório, ou ainda quando são doentes das unidades de saúde familiar na comunidade. Em todas estas unidades as equipas de profissionais planeiam a alta para as unidades da rede de cuidados e para cuidados na comunidade.

A alta dos doentes dos serviços de saúde constitui um processo de trabalho em equipa que visa prosseguir com a continuidade de cuidados na comunidade - sociais e de saúde - no sentido de melhorar a qualidade de vida do cliente, no que diz respeito ao tratamento, reabilitação e acompanhamento. O planeamento da alta representa as transições de níveis de prestação de cuidados da rede nacional de cuidados continuados integrados para os recursos informais e formais da comunidade. A alta do doente dá-se ou para junto da família, ou para respostas na comunidade, ou para as duas em conjunto, quando são mobilizados apoios formais complementares à ação da família (MASFRET, 2012).

Preparar a alta implica estabelecer um processo de relação de ajuda, considerar o doente em primeiro lugar, e definir objetivos concertados com as pessoas doentes, as famílias, instituições da comunidade e equipa de profissionais. Neste processo é essencial assegurar que as respostas pós-alta são adequadas a todos os níveis: saúde, social, psicológico e económico ${ }^{23}$. O planeamento da alta constitui-se como um método que implica acolhimento, aprofundamento da situação problema, plano de ação, acompanhamento e avaliação e a 
sistematização de instrumentos e técnicas de atuação, tais como a elaboração de notas de alta com informações sociais e relatórios sociais, mas também um processo de feedback constante do impacto das ações efetuadas no bem-estar do cliente.

Vejamos em pormenor alguns destes procedimentos e técnicas.

a) Acolhimento social: o acolhimento em Serviço Social, associado ao processo de admissão nas unidades ou nos cuidados, representa o primeiro atendimento social individualizado. O acolhimento, segundo Lewgoy e Silveira (2007), é o encontro entre sujeitos que se dá num espaço intercessor no qual se produz uma relação de escuta e responsabilização, a partir do qual se constituem vínculos e compromissos que norteiam os projetos de intervenção. $\mathrm{O}$ acolhimento não se limita ao ato de receber, ouvir, mas a uma sequência de atos que buscam a intervenção resolutiva.

O acolhimento requer o estabelecimento de uma relação empática com os doentes - compreensão do que sentem naquele momento, isto é, compreender o modo como os doentes percecionam o problema: qual o principal problema para o doente? O que sente na situação de doente? E qual o impacto para a sua vida?

É importante estabelecer também uma relação empática com a família e integrá-la na intervenção promover um acolhimento "amigo da família" - compreender o que sentem os familiares relativamente à doença dos seus familiares? E qual o impacto da mesma para a sua vida? Estas dimensões operativas da intervenção requerem que se tenha atenção às demandas dos princípios éticos e deontológicos. Assim é determinante informar os doentes do direito à autodeterminação - liberdade de escolha - e efetivação dessa escolha, confidencialidade e anonimato e consentimento para a intervenção social.

Qualquer cidadão tem o direito de ser integrado no processo de intervenção e para isso tem de ter conhecimento das regras de funcionamento de cada unidade ou equipa e os procedimentos da intervenção social. É importante também definir com o doente e com a família qual o seu papel no processo de intervenção. Contudo, nem sempre isso acontece, pois muitas vezes o doente é ainda representado como um objeto, que tem um número de cama e de processo.

Durante o acolhimento a recolha de informação sobre a situação psicossocial é determinante para se conhecer a vida pessoal, familiar e comunitária. Assim, é importante recolher dados objetivos quanto à situação pessoal, familiar, económica, habitacional, de suporte familiar e disponibilidades para proteger, cuidar e apoiar o doente ${ }^{24}$. O processo de acolhimento e de atendimento prossegue com a definição da atuação a seguir ${ }^{25}$.

b) Diagnóstico social: efetuado o acolhimento e existindo o consentimento dos doentes e familiares para a intervenção, assim como um conhecimento relativo da situação problema, é importante prosseguir com o aprofundamento das demandas através do diagnóstico. O mesmo implica uma série de atividades: reuniões de equipa multidisciplinar; articulação com as redes familiares; articulação com as redes informais da comunidade e articulação com os recursos formais nomeadamente com as instituições de referência para o cliente e para a família.

bi) Reuniões em equipa multidisciplinar

As reuniões de equipa multidisciplinar são importantes para a compreensão da situação e estabelecimento da visão integrada e holística. Nestas reuniões, não só se transmite informação sobre o cliente e família, mas acede-se a um conjunto de informações específicas de cada profissional, membros da equipa, que é necessário interpretar, e que complementam e aprofundam a análise. A discussão em torno dos casos é fundamental para a elaboração de hipóteses de intervenção e definição de estratégias a seguir em função do bemestar do doente. A colaboração multidisciplinar é indispensável para a defesa/advocacia de doentes ou grupos dos doentes e para o desenvolvimento de um verdadeiro trabalho de equipa baseado na confiança científica e técnica e para a interligação com os órgãos ou direções das instituições da rede e do doente e família.

bii) Articulação com redes de familiares

No aprofundamento do diagnóstico social é fundamental estabelecer uma relação de confiança privilegiada com a família. É indispensável que a família compreenda que a equipa multidisciplinar também está presente para defender os seus pontos de vista no processo de intervenção, só assim é possível que a mesma se constitua como parceira da intervenção e colabore ativamente em todo o processo.

O estabelecimento desta relação de confiança entre os doentes e os profissionais, não é fácil, pois nem sempre o ponto de vista das famílias é compreendido pela equipa técnica. Quantas vezes ouvem dizer que esta família não se interessa pelo familiar, que o deixou na unidade, que não o vai ver, que não quer saber, que não se implica na intervenção. Mas quantas vezes as profissionais escutam o que a família sente sobre o caso? Quais as dúvidas, os anseios e os medos da família? E o que a equipa já efetuou para escutar o que sente a família em vez do que pensa a família? Qual o suporte que as famílias têm efetivamente em todo o processo de intervenção?

O que queremos evidenciar é que as famílias necessitam também de espaços para serem ouvidas, acolhidas, que se sintam bem-vindas. As famílias, antes de se tornarem recursos para a intervenção, são também utentes ou doentes. Estas pessoas, famílias, demandam suporte, espaços onde sejam criadas ou reforçadas as suas competências como cuidadores, num novo reenquadramento das situações problema. Só 
assim as famílias poderão constituir-se como recursos para os seus membros. Neste nível são essenciais ações de formação para cuidadores, a integração dos familiares em grupos de autoajuda e um acompanhamento sistemático incondicional ${ }^{26}$.

biii) Articulação com a rede comunitária de serviços, de saúde e sociais

$\mathrm{Na}$ intervenção social a rede interinstitucional e intersectorial articulam-se e funcionam como uma verdadeira rede inter-serviços e inter-profissional. Este processo não é fácil, pois ainda não existe uma verdadeira cultura de articulação entre os organismos públicos, centrais, locais e as instituições da comunidade. Intervir nesta rede complexa é um desafio, sobretudo quando algumas instituições e profissionais ainda permanecem fechadas à rede social.

A articulação com as organizações da rede requer a elaboração de informações e relatórios escritos que validem as informações transmitidas oralmente e recolhidas através da observação. Este processo é importante para não só validar as evidências, mas também para responsabilizar as instituições pelo processo de intervenção. Implica também reuniões interprofissionais e intersectoriais, onde os casos possam ser discutidos, definidas as ações e as estratégias de intervenção.

c) Plano de ação: na organização do plano de ação destacamos dois procedimentos chave para a intervenção em cuidados continuados e no planeamento da alta: elaboração do plano individual de intervenção e a elaboração do plano individual de cuidados, este último é específico do Serviço Social. Em qualquer plano é importante ter presente as necessidades, os objetivos e os recursos. Os objetivos, tal como o diagnóstico social, estão sempre em aberto e decorrem da evolução da situação dos doentes, da família, da dinâmica processual da equipa e dos recursos disponíveis e necessários. A ideia é recompor e reformular os objetivos criando consensos, defendendo os interesses dos doentes. Os planos de intervenção e de cuidados sociais requerem objetivos exequíveis que tenham em conta a expetativa dos doentes e os recursos existentes ou a desenvolver.

É da competência do Assistente social definir estratégias de ação e metodologias específicas para que o plano de intervenção social e de cuidados sociais se concretize. O plano de intervenção, assim como o plano de cuidados, inclui indicadores de avaliação. Estes indicadores questionam, por exemplo, a efetividade do diagnóstico, dos objetivos, das ações, das metodologias, do processo de acompanhamento e dos impactos das mesmas.

d) Acompanhamento, execução, avaliação: o acompanhamento e execução do plano de cuidados implicam supervisão de apoio ou suporte, administrativa ou burocrática (CARVALHO, 2012d). No plano de cuidados são concretizadas ações de apoio ou suporte pelo profissional de Serviço Social e pela equipa multidisciplinar. A supervisão das mesmas é efetuada por um coordenador ou chefe de equipa.

O profissional de Serviço Social garante um apoio/suporte social adequado, desenvolvendo processos: a) informativos e de aconselhamento aos doentes e famílias sobre custos ou taxas para a adaptação à doença/perda, favorecendo ou apoiando grupos de suporte ou de auto ajuda e nos apoios em fim de vida; $b$ ) interventivos em situações de crise - em episódios agudos ou de agudização de doença, em episódios de violência, negligência ou trauma, em alterações de vida decorrentes da tomada de conhecimento de diagnósticos ou de mortes; c) educativos - em programas dirigidos ao doente/família e/ou cuidadores, em formação multidisciplinar, em programas interdisciplinares e de educação comunitária; d) trabalho de grupo - em função das necessidades e motivações de grupos de utentes/doentes dos serviços de saúde, ações vocacionada para a criação de trabalho voluntário ou de suporte ao já existente; e) na coordenação e mobilização de recursos e criação de recursos comunitários e f) continua a apoiar individualmente os doentes e família quando não há possibilidade de alta (DGS, 2006).

No processo de acompanhamento é importante estabelecer indicadores de avaliação, questionar se o diagnóstico está bem fundamentado; se os objetivos estão bem definidos; se as ações foram efetivamente bem programadas; quais os desvios e estratégias envolvidas nas ações que não estavam incluídas no plano inicial e que foram concretizadas e não concretizadas; quais os elementos novos que foram incluídos no diagnóstico. Saber se as metodologias foram as mais adequadas; se os recursos eram os mais apropriados; se os resultados obtidos foram os esperados. Este processo de questionamento e de avaliação contínua é determinante para refletir sobre o que, como, e porque fazemos e, ainda, para melhorar a qualidade da intervenção social, da equipa multidisciplinar e, consequentemente, a qualidade de vida do doente, da família e das organizações.

\section{Para concluir}

O Serviço Social tem uma relação implícita com as políticas de saúde e de cuidados continuados integrados em particular, destacando-se no planeamento da alta e na integração dos doentes na comunidade. $\mathrm{O}$ desenvolvimento destas respostas tem contribuído não só para a modernização do Serviço Nacional de Saúde em Portugal (CCI, 2013, p. 12), mas também para uma nova forma de olhar os serviços públicos pelos potenciais doentes, traduzida na consciencialização de que os cuidados são um bem comum a que podem recorrer. 
O Serviço Social tem-se destacado na democratização do acesso aos cuidados de saúde e sociais e evidenciado no trabalho em equipa e no modelo holístico de intervenção em saúde. Este processo tem possibilitado dar visibilidade à intervenção e à profissão do Serviço Social em saúde.

$\mathrm{Na}$ área da saúde e dos cuidados continuados integrados, o Serviço Social evidencia-se: na promoção da inclusão social de doentes e de famílias e na defesa do direito a ter cuidados; no combate à discriminação pela idade e no aumentado da autoestima dos doentes; na definição de estratégias criativas de poder que otimizam as motivações e capacidades e as possibilidades pessoais e sociais e na humanização dos serviços de saúde.

No âmbito da rede de cuidados continuados, destaca-se a importância da escuta activa perante os familiares, isto é, compreender quais são as suas perceções relativamente ao estado de saúde do utente, as suas expectativas relativas à reabilitação/manutenção do referido estado de saúde, e também saber como encaram esta situação em que se encontram. É de extrema importância que exista uma boa relação com os familiares do doente para o planeamento da alta. É fundamental que os familiares participem ativamente na intervenção.

Importa ainda realçar a importância em reunir, acompanhar, articular, comunicar telefonicamente com os familiares, para que haja uma boa relação com estes, mas acima de tudo para que se mantenham sempre próximos do doente, bem como de toda a sua envolvente e não se desresponsabilizem em algum momento do seu familiar.

A preocupação com o doente deve ser uma constante. Numa intervenção em equipa multidisciplinar o assistente social assume o papel de mediador e facilitador da intervenção e procura, dentro das respostas, a que melhor promove o bem-estar do doente.

Ao Serviço Social não basta ter um com método de intervenção, instrumentos e técnicas, é importante ter uma visão crítica e reflexiva sobre a mesma. Esta postura interventiva implica uma dupla dinâmica: mergulhar na realidade para compreendê-la, mas por outro lado manter um distanciamento que permita compreender, avaliar, refletir e construir novas formas de ação e conhecimento.

No momento de crise económica e social que atravessamos este duplo movimento é fundamental para defendermos os direitos dos cidadãos, doentes que necessitam dos cuidados desta rede, não só no acesso aos recursos, mas no usufruto efetivo de cuidados de qualidade. Só assim é possível capacitar os doentes e a comunidade onde se inserem. Espera-se que o Serviço Social possa desafiar as relações humanas e a efetiva participação das pessoas na sociedade num quadro de referência onde a cidadania ativa se destaque.

\section{Referências}

A REDE - A Revista da Unidade de Missão para os Cuidados Continuados Integrados. Plano individual de intervenção. Um Instrumento integrado de trabalho. n. 1, p. 10-11, dez. 2010. Disponível em: <http://www.rncci.min-saude.pt/SiteCollectionDocuments/ rede_dezembro_2010.pdf>.Acesso em: 12 jan. 2014.

BOQUINHAS, J. M. Políticas e sistemas de saúde. Coimbra: Almedina, 2012.

CAMPOS, A. C. de. Reformas da saúde. Coimbra: Almedina, 2008.

CAPARRÓS, M. J. E. Manual de trabajo social. Alicante: Aguaclara, 1992.

CARVALHO, M. I. L. B. de (Coord.). Serviço Social na saúde. Lisboa: Pactor, 2012a.

. Envelhecimento e cuidados domiciliários em instituições de solidariedade. Lisboa: Coisas de ler, 2012b.

. Cuidados continuados integrados e Serviço Social. In: CARVALHO, M. I. L. B. de (Coord.). Serviço Social na saúde. Lisboa:

Lidel; Pactor, p. 83-110, 2012c.

. Supervisão em Serviço Social, percurso para o desenvolvimento profissional e pessoal: um estudo exploratório. Locus Soci@ l:

Revista de Serviço Social, Política Social \& Sociedade, Lisboa, n. 4, p. 46-65, 2012 d.

. Contracorrentes em tempos de tempestades. O pensamento de Jane Addams e de Mary Richmond no Serviço Social. Em Pauta:

Teoria Social e Realidade Contemporânea, Rio de Janeiro, v. 10, n. 29, p. 157-170, 2012e.

. Serviço Social em Portugal: percurso cruzado entre a assistência e os direitos. Revista Serviço Social \& Saúde, Unicamp,

Campinas, v. IX, n. 10, p. 147-164, dez. 2010.

et. al. Actuação do Assistente Social Promotora de Cidadania na Transição Pós-Moderna. Revista Intervenção Social, Lisboa,

13/14, p. 271-302, 1998.

CCI - Cuidados Continuados Integrados - Saúde e Apoio Social. Implementação e Monitorização da Rede Nacional de Cuidados Continuados Integrados (RNCCI). Relatório Final. Março de 2013.

DMR - Departamento de Modernização e Recursos da Saúde. Circular normativa n. 8, de 16 maio de 2002. Departamento de Modernização e Recursos da Saúde do Ministério da Saúde. Lisboa, 2002.

DECRETO DE LEI. n. 22 de 2011, Cria a Rede Nacional de Cuidados Continuados Integrados de Saúde Mental, publicado no Diário da República. 
n. 101 de 2006, Cria a Rede Nacional de Cuidados Continuados Integrados, publicado no Diário da República I-Série A a 6 de Junho.

.n. 281 de 2003, Cria a Rede de Cuidados Continuados, publicado no Diário da República I-Série A a 8 de Novembro.

DESPACHO n. 26 de 1986, publicado no diário da republica II série, de 30-06-1986.

. $n^{\circ} 5081$ de 2005, publicado no diário da republica II série, de 09-03-2005.

n. 8958/2013, publicado no Diário da República, 2. ${ }^{a}$ série, n. 130, 9 de julho de 2013.

DESPACHO CONJUNTO n. 204 de 1996, publicado no Diário da Republica, II série, nº 204, em 3 de Setembro.

. n. 166 de 1994, Criação do Programa de Apoio Integrado a Doentes, publicado a 20 Julho.

n. 259 de 1997, Regulamentação do Programa de Apoio Integrado a Doentes, publicado no Diário da República, no 192 a 21 Agosto. n. 407 de 1998, Aprova as Orientações Reguladoras da Intervenção Articulada do Apoio Social e dos Cuidados de Saúde Continuados, Ministério da Saúde, Ministério do Trabalho e da Solidariedade Social, publicado a 18 de Junho.

DGS - Direcção-Geral da Saúde. Manual de boas práticas dos assistentes sociais da saúde na Rede Nacional de Cuidados Continuados Integrados. Lisboa: DGS, 2006.

DOMINELLI, L. Serviço Social com idosos. Intervenção orientada para o mercado ou para os serviços universais? In: CARVALHO, M. I. L. B. de. Serviço Social no envelhecimento (Coord.). Lisboa: Pactor, p. 67-80, 2013.

FALEIROS, V. P. O que Serviço Social quer dizer? Serviço social e sociedade, n. 108, p. 748-761, out./dez. São Paulo, 2011.

GARCIA, F.; ROMERO, L. P. de L. Trabajo Social individualizado, metodologia de interventión. Madrid: Ediciones Académicas, 2012. GOMES, V. O planeamento das altas em unidades de cuidados continuados de longa duração e manutenção: um estudo de caso na unidade maturidade em Rio Maior. Dissertação (Mestre em Gerontologia Social) - Universidade Lusófona, Lisboa, Portugal, 2013.

LEWGOY, A. M. B.; SILVEIRA, E. M. C. A entrevista nos processos de trabalho do assistente social. Revista Textos \& Contextos, Porto Alegre, v. 6, n. 2, p. 233-251, jul./dez. 2007.

LOUREIRO, I.; MIRANDA, N. Promover a saúde. Dos fundamentos à acção. Coimbra: Almedina, 2010.

LOPES, M. A. et al. Serviço Social e qualidade em contexto hospitalar. In: CARVALHO, M. I. L. B. de (Coord.). Serviço Social na Saúde, 25-54. Lisboa: Pactor, 2012.

MASFRET, D. C. O Serviço Social de saúde e o planeamento da alta para a continuidade de cuidados na comunidade. In: CARVALHO, M. I. L. B. de (Coord.). Serviço Social na saúde. Lisboa: Lidel; Pactor, p. 55-80, 2012.

OMS - Organização Mundial da Saúde. Declaração Política do Rio sobre Determinantes Sociais da Saúde. In: CONFERÊNCIA MUNDIAL SOBRE DETERMINANTES SOCIAIS DA SAÚDE, 19-21 de outubro de 2011. Rio de Janeiro, 2011. Disponível em: <http://www.who.int/sdhconference/declaration/Rio_political_declaration_portuguese.pdf >. Acesso em: 12 jan. 2014.

PAYNE, M. Humanistic Social Work: Core Principles in Practices. Great Britain: Palgrave Macmillan, 2011.

PORTUGAL. Ministério da Saúde. Lei n. 52, de 5 de Setembro de 2012 - Lei de Bases dos Cuidados Paliativos e cria a Rede Nacional de Cuidados Paliativos. Diário da República, n. 172, Série I, p. 2012.

PORTUGAL. Ministério da Saúde. Lei n. 56, de 15 de setembro de 1979. Cria o Serviço Nacional de Saúde. Diário da Republica, série I, n. 214, p. 2357-2363, 1979.

REIS, J. C. O que é a saúde? Significações pessoais, modelos científicos e educação para a saúde. Lisboa: Nova Veja, 2005.

RESOLUÇÃO DO CONSELHO DE MINISTROS n. 84 de 2005, Princípios de Estruturação dos Cuidados de Saúde às Pessoas Idosas e Dependentes, Publicado no Diário da República, I série-B, n. 81 de 27 de Abril de 2005.

SANTOS, C. M.; SOUZA FILHO, R.; BACKX, S. S. A dimensão técnico-operativa do Serviço Social: questões para reflexão. In: SANTOS, C. M.; BACKX, S. S.; GUERRA, Y. A. D. (Org.). A dimensão técnico-operativa no Serviço Social: desafios contemporâneos. Juiz de Fora: Ed. da UFJF, p. 15-37, 2012.

\section{Notas}

1 Atualmente esta rede é composta por hospitais centrais e distritais - gerais; hospitais especializados - Institutos de oncologia, infância, maternidades; agrupamentos de centros de saúde onde estão integradas as Unidades de Saúde Familiares, e também o sistema Sim Cidadão; assim como a rede de cuidados continuados e programas de promoção da saúde. Também inclui serviços de saúde mental, integração psicossocial dos doentes e apoio a famílias e serviços no tratamento da adição - toxicodependência e alcoolismo, assim como programas de promoção da saúde e Rede de cuidados continuados.

2 OServiço Nacional de Saúde, implementado em Portugal, estálonge de ser pacífico. Desde a sua fundação foi sempre alvo de críticas, uma das quais se refere a seu custo elevado para as finanças públicas. Contudo, é também assumido que este sistema, de base universal, contribuiu grandemente para o desenvolvimento em Portugal, tendo em conta indicadores como a diminuição da taxa de mortalidade infantil e o aumento de anos de sobrevida na velhice.

3 Dados inscritos na despesa corrente em cuidados de saúde por tipo de agente financiador para 2012 (Pordata, 2013), revelam que o Estado tem diminuído o financiamento nesta área e que as famílias têm aumentado o custo com a saúde.

4 Esta articulação é essencial para que os doentes possam aceder à informação rápida aos diversos tipos de cuidados, mas também para aumentar a eficácia de serviços públicos. 
5 Foi regulamentado pelos Despachos Conjuntos n. 259, de 21 de agosto de 1997; n. 407, de 18 de junho de 1998; e n. 726, de 16 de outubro de 1998.

6 As respostas que estavam programadas eram as seguintes: Centro de apoio a dependentes, CAD; Serviço de apoio domiciliário, SAD; Formação de recursos humanos, FORHUM; Serviço telealarme; Termalismo Sénior e apoio nos passes para a terceira idade.

7 Estas duas respostas foram regulamentadas, em 1998, pelo Despacho Conjunto n. 407, o qual criou o serviço de apoio domiciliário integrado,ADI, e a unidade de apoio integrado, UAI, destinados a pessoas mais idosas, com deficiência e aquelas com diagnóstico de perturbação/doença mental.

8 O programa, com uma duração de implementação de 10 anos, 2006 a 2016, tinha o propósito de cobrir todo o território nacional, sendo da responsabilidade dos agentes as políticas a nível central, local e comunitário - governo, autarquias e organizações da sociedade civil, não lucrativas e lucrativas.

9 Estes lugares são distribuídos da seguinte forma: em unidades de convalescença, 867; de média duração e reabilitação, 1820; de longa duração e manutenção, 3031; e em unidades de paliativos, 193. Também o número de equipas de gestão das altas nos hospitais aumentou de 60 para 80 , assim distribuídas: no norte do país 15; no centro do país 17; Lisboa e vale do tejo 31; Alentejo 5 e no algarve 5 (CCI, 2013).

10 Em 2012 existiam 162 equipas no Norte, 69 equipas no Centro, 84 equipas em Lisboa e vale do tejo no Alentejo, e 33 equipas no Algarve (CCI, 2013).

11 Nos últimos anos foram construídas outras redes de cuidados específicas, nomeadamente a rede de cuidados continuados para a saúde mental em 2010 (Decreto de Lei n. 8, de 28 de janeiro) e a rede de cuidados continuados em cuidados paliativos em 2011 (Decreto de Lei n. 22, de 10 de fevereiro). Contudo, devido à crise financeira do Estado nem uma nem outra estão a ser desenvolvidas.

12 Compete ao gabinete do cidadão: a) Verificar as condições de acesso aos cuidados de saúde; b) Promover e divulgar os direitos e deveres dos cidadãos; c) Atender pessoalmente os cidadãos que o solicitem e/ou que pretendam apresentar exposições orais e passá-las a escrito; d) Assegurar o registo e o tratamento das exposições, reclamações, sugestões e elogios, independentemente do local e da forma de apresentação; e) Assegurar meios de participação dos cidadãos, designadamente através de caixas de sugestões, correio eletrónico e livro de reclamações; f) Verificar regularmente o grau de satisfação dos cidadãos que contactaram com as unidades prestadoras de cuidados de saúde e serviços integrados no Serviço Nacional de Saúde. (Despacho n. 8958/2013, publicado no Diário da República, 2.a série, n. 130, 9 de julho de 2013).

13 OSistema SIM-Cidadão organiza-se segundo os seguintes princípios gerais: a) Princípio da participação, valorizando as exposições, reclamações, sugestões e elogios apresentados pelos cidadãos relativamente às unidades e serviços integrados no SNS; b) Princípio da resposta ao cidadão, como garante da comunicação da decisão que recaiu sobre a exposição apresentada; c) Princípio da transparência, contemplando a disponibilização do sistema aos cidadãos através da internet, em acesso condicionado a registo, assegurando ao interessado o acompanhamento das exposições, reclamações, sugestões e elogios por si apresentados; d) Princípio da colaboração, disponibilizando os recursos necessários à mediação dos direitos, expectativas e interesses legítimos dos cidadãos, ao registo e tratamento oportuno e adequado das exposições, reclamações, sugestões e elogios; e) Princípio da ética, preconizando a salvaguarda dos direitos e deveres dos cidadãos, designadamente em matéria de proteção da

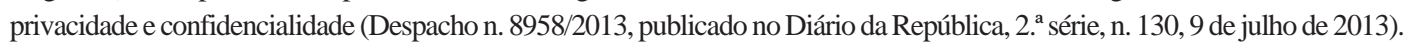

14 As primeiras assistentes socias a exercerem a profissão atuaram no Hospital de Coimbra em 1941, no Hospital Júlio de Matos em 1942, seguindose outros hospitais e unidades de saúde, IPO em 1948 (LOPES et al., 2012).

$15 \mathrm{Na}$ área da saúde compete ao profissional de Serviço Social: identificar e analisar os problemas e as necessidades de apoio social dos utentes diagnósticos, como proceder ao acompanhamento e apoio psicossocial dos utentes e das respetivas famílias - de planos de intervenção social; procederà investigação, estudo e conceção de processos, métodos e técnicas de intervenção social; participar na definição, promoçãoe concretização das políticas de intervenção social; definir, elaborar, executar e avaliar programas e projetos de intervenção comunitária; assegurar a continuidade dos cuidados sociais a prestar, em articulação com os parceiros da comunidade; envolver e orientar utentes, famílias e grupos no autoconhecimento ena procura dos recursos adequados às suas necessidades; articular-se com os restantes profissionais do serviço ou estabelecimento-humanização; relatar, informar e acompanhar, sempre que necessário e de forma sistemática, situações sociais problemáticas (Circular Normativa n. 8, do Departamento de Modernização e Recursos da Saúde do Ministério da Saúde, 16 de maio de 2002).

16 Os fundamentos da intervenção individualizada encontram-se nas obras de Mary Richmond e das suas seguidoras, nomeadamente Amy Gordon Hamilton, Charllotte Towle, Florence Holis e Helen Perlman (CAPARRÓS, 1992; GARCIA; ROMERO, 2012). Mary Richmond introduziu no Serviço Social uma dimensão científica e profissionalizou a assistência social. Construiu uma teoria e uma prática fundadas no conhecimento científico, em função daquilo que era a ideia de inovação social e científica do seu tempo (CARVALHO, 2012e).

17 A visão do Serviço Social individualizado, de Mary Richmond, foi influenciada por teorias sociais, pelo pensamento de H. de George Mead e pelas Teorias do self expandido. Estas teorias constituem os fundamentos do Serviço Social individualizado. Para além desta influência, o seu trabalho foi também apoiado pelas correntes interacionistas e pragmatistas da Escola de Chicago (Carvalho, 2012e). A intervenção individualizada foi permeável a outras influências e correntes de pensamento das ciências sociais (GARCIA; ROMERO, 2012, p. 38). Garcia e Romero (2012, p. 39) afirmam que este tipo de intervenção, quando foi adotado na Europa, ganhou uma enfase psicossocial.

18 A intervenção psicossocial visa: compreender as relações interpessoais e da conduta humana; potenciar conhecimentos sobre as necessidades básicas para que a pessoa possa desenvolver-se de forma adequada mediante a mudança do meio; proporcionar elementos de compreensão do desenvolvimento humano; refletir sobre os fatores que podem produzir uma evolução no desenvolvimento da pessoa (regressão) ou permanência numa determinada etapa do desenvolvimento; permitir entender os mecanismos defensivos das pessoas perante os problemas; desenvolver e entender as relações sociais e compreender a evolução psicoafectiva dos indivíduos como produto da interação social do grupo família com o ambiente (CAPARRÓS, 1992).

19 Na rede de cuidados continuados, os assistentes sociais são profissionais, membros das equipas de saúde, cuja função é de acompanhar a intervenção social em unidades de cuidados continuados na comunidade; cuidados de saúde e sociais nas unidades de internamento e em equipas 
de planeamento das altas nos hospitais. Em qualquer destes campos de ação a intervenção consubstancia-se fundamentalmente pelo planeamento das altas, seja no acesso às unidades residenciais, seja em cuidados continuados de saúde no domicílio.

20 Santos et al. (2008, p. 19) alertam para o fato de a dimensão técnico-operativa não dizer respeito exclusivamente a instrumentos e técnicas, mas mobiliza as dimensões teórico-metodológicas - para analisar o real e investigar as novas demandas - e a dimensão ética e política - permitindo avaliar as alternativas viáveis para a realização da ação, bem como projetar a ação em função dos valores e finalidades e avaliar as consequências da ação, considerando as demandas da população e os contextos, de modo a considerar a totalidade do Serviço Social.

21 Oplano individual de intervençãoé efetuado após uma avaliação integral da equipa multidisciplinar com a identificação das necessidades do utente e cuidador principal periodicamente atualizado (A REDE, 2010). O plano individual de intervenção, expressa os cuidados a prestar de acordo com os objetivos a atingir e inclui o registo sistemático dos cuidados prestados por cada elemento interventor, datado e rubricado, a avaliação semanal e eventual aferição do plano individual de intervenção e a nota de alta (GOMES, 2013).

22 Oplano individual de cuidados é mais específico, refere-se aos cuidados resultantes da análise social da situação e implica ações de acompanhamento psicossocial e a preparação da continuidade de cuidados, sendo que a especificidade da sua ação em cada tipo de Unidade de Internamento depende da natureza da doença, estádio da sua evolução, vocação da instituição, tipos de cuidados e serviços que esta presta e tempo previsto de internamento (GOMES, 2013).

23 Como é referido no documento da DGS (2006), o planeamento da alta requer: uma organização comunitária - para a satisfação de necessidades dos cidadãos na prestação de cuidados ou serviços; o uso de metodologias de intervenção que visam o reforço ou o desenvolvimento do poder organizativo das populações na satisfação das suas necessidades; a articulação e/ou cooperação entre recursos (públicos; privados lucrativos ou não lucrativos; formais ou informais); a prestação dos cuidados e dos serviços de proximidade necessários ao maior bem-estar, autonomia e inserção social ou sócio-profissional dos doentes/dependentes.

24 No acolhimento/atendimento social identificam-se os indicadores de risco e de proteção (CARVALHO, 2012c) e analisam-se as principais questão/problema para os clientes, para a família, para os profissionais, e para as organizações. Esta análise implica verificar as semelhanças e diferenças das abordagens dos vários intervenientes. Em função desses indicadores, mais do que informar sobre direitos sociais (pensões, complementos, apoios e outras medidas que sejam importantes para cada caso), é determinante facilitar o acesso a esses direitos.

25 Todo este processo é registado numa ficha adequada que pode ser digital ou em papel e contribuirá para plano individual de intervenção e o plano individual de cuidados.

26 É indispensável, que se identifiquem aspetos comuns e que se trabalhe a partir dessa ideia. Um ponto comum pode ser o de trabalhar em função do bem-estar do cliente. É importante que a família se sinta fortalecida e apoiada na comunidade, por isso o estabelecimento de canais de informação com as redes comunitárias é determinante. Por exemplo, o acesso a serviços e a resolução de questões para o usufruto de respostas (documentos, consultas, serviços sociais, cuidados, apoio especializado).

Maria Irene Lopes B. de Carvalho

mariacarvalho21@hotmail.com

Doutora em Serviço Social pelo Instituto Universitário de Lisboa (Iscte)

Docente no curso de Serviço Social e no Mestrado de Gerontologia Social na Universidade Lusófona de Lisboa

\author{
Universidade Lusófona de Humanidades e Tecnologias \\ Faculdade de Ciências Sociais e Humanas \\ Curso de Serviço Social \\ Campo Grande, 376 \\ Lisboa - Portugal \\ CEP: $1749-000$
}

